\title{
The Effects of Employment while Pregnant on Health at Birth
}

\author{
Charles L. Baum II* \\ Middle Tennessee State University, Murfreesboro, TN
}

\begin{abstract}
Today, many pregnant women take a brief period of time off from work to give birth. In this paper, I identify the effects of pregnancy employment on health at birth. My initial results show that pregnancy employment has beneficial effects. However, these effects often become statistically insignificant when I control for earnings from pregnancy employment, when I exclusively examine women employed prior to the pregnancy, and when I examine siblings in fixed effects models. I conclude that beneficial effects of pregnancy employment are partially due to increased family income via earnings during the pregnancy and partially due to unobserved heterogeneity. There is no evidence that increased female labor force participation adversely affects health at birth.
\end{abstract}

Key words: labor supply, pregnancy employment, health at birth

JEL category: J1, J2, J3

*Charles L. Baum II, Associate Professor Department of Economics and Finance, Middle Tennessee State University, Murfreesboro, TN 37132, phone: 615-898-2527, fax: 615-898-5596, email: cbaum@mtsu.edu 


\section{Introduction}

More women are working in the marketplace today than ever before. Specifically, about 60 percent of women are currently in the labor force, which is almost a 50 percent increase from 30 years ago (Bureau of Labor Statistics, 2000). Much of this increase is due to mothers participating in the labor force. In fact, 61 percent of all mothers are working within three years after their child's birth (Bureau of Labor Statistics, 2000), with about half of these mothers returning to work within the first three months after giving birth (Klerman and Leibowitz, 1990). Many of these women find that marketplace work and household production increasingly compete for their time. Consequently, many employed pregnant women return to work quickly after giving birth to keep their jobs, taking only a brief period of time off from work. The proportion of women in the labor force may be further increased by welfare reform's recent emphasis on moving recipients to work.

This demographic trend is important because a woman's work decisions may have an effect on her child. In fact, some researchers have found that maternal employment during a child's first year significantly hinders cognitive development (Baum, 2003; Blau and Grossberg, 1992; and Desai, Chase-Lansdale, and Michael, 1989). ${ }^{1}$ Others have found that a woman's behaviors during the pregnancy (cigarette smoking, illegal drug use, and receipt of prenatal care) have important effects on her child's health at birth. ${ }^{2}$ It follows that a woman's employment during the pregnancy may have an effect on her child's health, though virtually no economist has examined the "pregnancy employment-health at birth" link.

\footnotetext{
${ }^{1}$ Baum's (2003) negative effects are partial effects -- holding family income constant. Increased family income via maternal employment at least partially offsets maternal employment's negative effects in his models. Smolensky and Gootman (2003) summarize this literature and conclude that negative effects on infants are most likely to occur for maternal employment during the child's first year.

${ }^{2}$ For the effects of cigarette smoking, see Rosenzweig and Schultz (1983b), Corman, Joyce, and Grossman (1987), and Rosenzweig and Wolpin (1991), for illegal drug use, see Joyce, Racine, and Mocan (1992), Mocan and Topyan (1995), and Kaestner, Joyce, and Wehbeh (1996), and for the receipt of prenatal care, see Grossman and Joyce (1990), Frank et al. (1992), and Joyce (1994).
} 
The medical literature shows that exposing pregnant women to excessive physical activity, chemicals, infectious diseases, radiation, physical elements, and stress will have adverse effects on health at birth (Feinberg, 1998). For example, Luke et al. (1995), Colie (1993), Mamelle, Lauman, and Lazar (1984), Klebanoff, Shiono, and Rheads (1990), and Teitelman et al. (1990) find that prolonged standing, strenuous physical exertion, and heavy lifting increase the incidence of preterm birth and low birth weight; McMichael et al. (1986) and Emhart et al. (1992) find that exposure to chemicals such as lead increases the incidence of preterm birth and low birth weight; Pass et al. (1982), Ahlfors et al. (1981), Rodis et al. (1990), Brunell (1983), and Preblud, Bregman, and Vemon (1985) find that common viruses transmitted to the fetus from the mother potentially result in a number of mental and motor disabilities; Dunn et al. (1990) find that prenatal radiation exposure increases the incidence of mental disabilities; Mamelle, Lauman, and Lazar (1984) find that physical elements such as smoke, dust, vapors, heat, and noise increase the incidence of preterm birth; and Luke et al. (1995) find that stress and fatigue increase the incidence of preterm birth.

From the medical literature, it follows that if marketplace work during the pregnancy (referred to hereafter as pregnancy employment) exposes expectant mothers to the potentially harmful elements mentioned above, then it may detrimentally affect health at birth. Conversely, pregnancy employment may enhance birth outcomes by increasing family income via pregnancy earnings. Increased family income potentially benefits health at birth by facilitating the purchase of health inputs such as prenatal care.

In this paper, I estimate the effects of pregnancy employment on health at birth. I measure health at birth with the incidence of low birth weight and preterm birth. Then, I explore the mechanisms through which pregnancy employment's effects operate. In particular, I investigate two ways through which pregnancy employment might affect health at birth: by changing pregnancy behaviors (such as cigarette smoking, alcohol consumption, and prenatal medical care visits) and by increasing family income via pregnancy earnings. I also explore the 
effects of pregnancy employment by trimester, and I estimate a set of low birth weight models that control for preterm birth to explore whether pregnancy employment affects birth weight through gestation length or utero growth. Further, to investigate the potential for unobserved heterogeneity bias, I re-estimate the models on a more homogeneous subset of women who were employed prior to their pregnancy. Additionally, I estimate sibling fixed effects models to control for time-invariant sources of unobserved characteristics. If taking time off from work is beneficial to infant health (and if some working pregnant women do not wish to end their careers to give birth), then this would strengthen the case for finding ways for employed women to take leave from work while pregnant.

My initial results with the full sample show that pregnancy employment has some beneficial effects on health at birth. Controlling for other pregnancy behaviors does not explain pregnancy employment's beneficial effects. However, statistically significant effects often disappear when I control for pregnancy earnings and when I examine a subset of women who were employed prior to the pregnancy and a subset of siblings in fixed effects models. This suggests that any beneficial effects of pregnancy employment are partially due to increased family income via pregnancy earnings and partially due to unobserved heterogeneity. I conclude that the increased labor force participation rate of women has not had detrimental effects on health at birth.

The remainder of the paper is as follows: I formulate the theoretical model in the next section, I present the existing evidence in section III, I describe the data and empirical methodology in section IV, I present and discuss the results in section V, and I conclude the paper in section VII.

\section{Theoretical Background}

Following the work of Becker (1965, 1981), Grossman (1972), Becker and Tomes (1986), and Tomes (1981), I assume that the household derives utility from health at birth (Y), other household consumption (X), and leisure (L), 


$$
\mathrm{U}(\mathrm{Y}, \mathrm{X}, \mathrm{L})
$$

subject to a time constraint,

$$
\mathrm{T}=\mathrm{H}+\mathrm{L},
$$

where $\mathrm{T}$ is the amount of time available and $\mathrm{H}$ is hours of marketplace work, and a budget constraint,

$$
w H+N=P_{M} M+P_{X} X
$$

where $\mathrm{w}$ is the market wage, $\mathrm{N}$ is nonwage income, $\mathrm{M}$ is a vector of purchased health inputs (such as prenatal physician care), $\mathrm{P}_{\mathrm{M}}$ is a vector of health input prices, and $\mathrm{P}_{\mathrm{X}}$ is a vector of the prices of other consumption goods. ${ }^{3}$ Given these constraints, households allocate resources optimally between other household consumption, leisure, and investments in health.

Health at birth (Y) can be viewed as an output from a "health" production function,

$$
\mathrm{Y}=\mathrm{F}\left(\mathrm{Y}_{0}, \mathrm{M}, \mathrm{L}, \mathrm{S}, \mathrm{Z}\right)
$$

where $\mathrm{Y}_{0}$ is baseline health (a genetic health endowment), $\mathrm{L}$ is the pregnant women's nonmarket time (referred to above as leisure), $\mathrm{S}$ is a vector of other pregnancy behaviors (such as cigarette smoking and alcohol consumption), and $\mathrm{Z}$ is a vector of exogenous environmental conditions (such as the number of hospital beds in the community). Given this setup, the woman's nonmarket time (leisure) is assumed to have a direct effect on health at birth. In addition, I explore whether nonmarket time has an indirect effect through other arguments of the health production function such as purchased health inputs and pregnancy behaviors. It is assumed that health at birth is increasing in purchased health inputs such as prenatal physician care and is decreasing in certain pregnancy behaviors such as cigarette smoking and alcohol consumption. However, the effect of nonmarket time (or, conversely, pregnancy employment) is ambiguous for reasons to be explained below.

\footnotetext{
${ }^{3}$ Pregnancy behaviors such as cigarette smoking and alcohol consumption will enter the household utility function as part of other household consumption $(\mathrm{X})$.
} 
Pregnancy employment may have an effect on health at birth by influencing other pregnancy behaviors. For example, pregnancy employment may leave pregnant women with less time to receive prenatal physician care. ${ }^{4}$ Waiting at a clinic for a doctor visit may take a substantial portion of a day, which may conflict with work schedules. Conversely, employed women may be more likely to seek prenatal care if such employment includes fringe benefits that provide better access to health care. Continuing, pregnancy employment may provide pregnant women with less time to engage in healthy pregnancy behaviors such as exercise, sleep, and bed rest later in the pregnancy. Additionally, pregnancy employment may affect other behaviors such as cigarette smoking and alcohol abuse -- if these behaviors are prohibited at work, then pregnancy employment would reduce them (at least during work hours).

Further, employment while pregnant may enhance health at birth by increasing family income via pregnancy earnings. Increased family income may enhance health at birth by facilitating the purchase of health inputs such as medical supplies and prenatal physician care, and, for example, at least some evidence indicates that prenatal care enhances birth outcomes (Grossman and Joyce, 1990; Frank et al., 1992; Joyce, 1994; Warner, 1995; Frisbie, Forbes, and Pullum, 1996; and Liu, 1998). ${ }^{5}$ Further, increased family income may lift (or keep) the family out of poverty. This would improve birth outcomes to the extent that poverty causes undesirable birth outcomes. Certainly poverty has been associated with less healthy children. For example, poverty is associated with an increase in the probability of infant mortality, low birth weight, and poor health at birth (Currie and Cole, 1993; Guo and Harris, 2000; and Stockwell, Swanson, and

\footnotetext{
${ }^{4}$ Many have found that health at birth is enhanced by prenatal care (Grossman and Joyce, 1990; Frank et al., 1992; Joyce, 1994; Warner, 1995; Frisbie, Forbes, and Pullum, 1996; and Liu, 1998). Currie and Grogger (2002) note that prenatal care can reduce the incidence of premature birth by detecting and treating vaginal infections with antibiotics. Further, Currie and Grogger note that prenatal care can be used to monitor (and encourage appropriate) maternal weight gain, which is associated with infant birth weight.

${ }^{5}$ However, others do not find beneficial effects of prenatal care (Rosenzweig and Schultz, 1983a; and Corman, Joyce, and Grossman, 1987).
} 
Wicks, 1988). ${ }^{6}$ Poverty is also associated with an increased prevalence of infectious diseases, chronic health conditions, and injuries (Egbuonu and Starfield, 1982; and Pless, Verreault, and Tenina, 1989) and an increased prevalence of smoking cigarettes, drinking alcohol, and using illegal drugs (Klerman, 1991; and Jones and Lopez, 1990). ${ }^{7}$ Those with low incomes are more likely to live in areas with fewer medical facilities and less likely to have health insurance; consequently, low-income pregnant women are less likely to obtain timely prenatal care (Cramer, 1995). However, if poverty does not cause undesirable birth outcomes, then family income will not have beneficial effects by reducing poverty.

It is not clear whether the effects of employment during the first, second, or third trimester are greatest. One might argue that the effects of pregnancy employment early in the pregnancy should be greatest. Certainly this is the period during which pregnant women are first recommended to receive prenatal care, and many studies have found that the timing of prenatal care during the pregnancy affects health at birth (Rosenzweig and Schultz, 1983b; Grossman and Joyce, 1990; Frank et al., 1992; and Warner, 1995) because early detection aids in identifying and correcting prenatal health problems. Conversely, employment late in the pregnancy may be more important if factors such as bed rest are significant determinants of health at birth. Certainly premature labor and vaginal hemorrhaging often occur later in the pregnancy. Further, Chomitz et al. (1995) note that most fetal growth occurs in the third trimester. Examining cigarette smoking, for example, the medical literature has found that smoking cessation in the first trimester improves birth outcomes, but quitting cigarette smoking as late as the third trimester has a significantly beneficial effect on birth weight as well (Lightwood, Phibbs, and Glantz, 1999; Cornelius, Taylor, Geva, and Day, 1995; and Hueston, Mainous, and Farrell, 1994).

\section{Existing Evidence}

\footnotetext{
${ }^{6}$ This has also been found with aggregate data. For example, Pritchett and Summers (1996) find that infant mortality is decreasing with a country's income per capita.

${ }^{7}$ For more on the effects of cigarette and alcohol prices on consumption, see Grossman (2001).
} 
The effects of maternal employment on children have been widely studied in the sociology and economics literatures. However, the vast majority of these studies have examined the effects of maternal employment on measures of child development (such as the Peabody Picture Vocabulary Test) rather than on child health. ${ }^{8}$ A separate line of research has examined child and infant health, but these studies have not examined the effects of maternal employment (or employment while pregnant) on the health outcomes. Instead, studies examining infant health look at the effects of other maternal behaviors during the pregnancy such as cigarette smoking (Rosenzweig and Schultz, 1983b; Corman, Joyce, and Grossman, 1987; and Rosenzweig and Wolpin, 1991), illegal drug use (Joyce, Racine, and Mocan, 1992; Mocan and Topyan, 1995; and Kaestner, Joyce, and Wehbeh, 1996), and receipt of prenatal care (Grossman and Joyce, 1990; Frank et al., 1992; Joyce, 1994; Warner, 1995; and Liu, 1998).

I seek to improve upon the existing literature by developing a specification of the determinants of health at birth that includes pregnancy employment. Specifically, I identify each pregnant woman's employment status in each week of the pregnancy. Then, I estimate the direct effect of pregnancy employment on health at birth as well as indirect effects through other pregnancy behaviors and earnings from pregnancy employment. I also explore the effects of the timing of pregnancy employment and whether pregnancy employment affects health at birth by affecting gestation length or utero growth. Further, I control for unobserved heterogeneity bias by re-estimating the models on a subset of women who were employed prior to the pregnancy and by comparing siblings in fixed effects models.

\section{Data and Empirical Technique}

I use data from the National Longitudinal Survey of Youth (NLSY) because it collects extensive information on each respondent's labor market experiences as well as information about each respondent's children (particularly about health at birth). The NLSY began annually

\footnotetext{
${ }^{8}$ Hill and O’Neill (1994), Blau and Grossberg (1992), Mott (1991), Desai, Chase-Lansdale, and Michael (1989). For a summary of this literature, see Smolensky and Gootman (2003).
} 
interviewing 12,686 individuals who were between the ages of 14 and 21 in 1979, and the survey remains in progress. The original NLSY sample contained 6,283 women and an oversample of blacks, Hispanics, low-income whites, and military personnel. The military sample was dropped in 1984 and the low-income white sample was dropped in 1990. The NLSY User's Guide reports that by the year-2000 survey, 8,323 children had been born to interviewed mothers. The NLSY first collected information about health at birth for the youngest child in the 1983 survey. Since that time, the NLSY has collected this information for births since the last interview. Of the 8,323 births, 5,771 were covered by the 1983 or successive surveys. Of those 5,771 births, 4,185 provide the necessary information to create the covariates. Since most of the births that are not included come from pre-1983 surveys, my sample disproportionately under-represents births to relatively young NLSY mothers.

In addition, I eliminate birth-observations if the expectant mother reports employmentlimiting or precluding health problems. If women with such health problems were included (and if employment-limiting or precluding health problems were associated with or due to fetal health problems), then pregnancy nonemployment might appear detrimental to health at birth when, in fact, this association would be due to other factors. The remaining sample contains 3,753 births. For similar reasons, I also eliminate birth-observations for which sonograms and/or amniocenteses indicate fetal health problems such as abnormal growth and birth defects. These observations have pre-existing health problems, and such health problems may influence pregnancy employment. ${ }^{9}$ The final sample contains 3,546 birth-observations used in the estimation.

The NLSY collects extensive information on each respondent's labor market experiences. In particular, the NLSY identifies each respondent's employment status in each week covered by the survey. Because the NLSY also reports the week in which each child was born, I am able to

\footnotetext{
${ }^{9}$ Unfortunately, not every expectant mother received a sonogram or amniocentesis (or information on such tests was unknown). I control for this with dummy variables indicating that sonogram results and amniocentesis results are not available.
} 
construct a work history for each woman that identifies her employment status in each week of her pregnancy. ${ }^{10}$ NLSY mothers determine the gestational age of their child and report this in the NLSY survey questionnaire (by reporting the number of weeks before or after the due date the baby was born). The work history just described also identifies the number of hours typically worked in each week. Thus, it is possible to determine not only whether pregnant women work but also the intensity of their work.

I create multiple variable specifications to measure employment while pregnant. In some models, I define employment as a dummy variable that equals 1 if the woman worked while pregnant (and zero otherwise). In other models, I specify the employment variable to equal the proportion of hours worked during the pregnancy. Specifically, this variable equals the average weekly hours worked divided by 40 . Thus, increasing this variable from 0 to 1 shows the effect of increasing weekly work hours from 0 to 40 . Because the average number of hours worked can be greater than 40 , this specification is flexible enough to pick up overtime hours. This is important because moderate employment while pregnant may not have a harmful effect on child health but excessive employment while pregnant may be detrimental. Finally, I create categorical pregnancy employment variables to pick up non-linear trends. In particular, the categorical variables identify the effect of pregnancy employment for the following categories of average weekly hours of work: no work, greater than 0 and less than 20 weekly hours of work, 20 to 40 weekly hours of work, and 40 or more weekly hours of work. (In the analysis, the excluded category is zero hours of work during the pregnancy.)

\footnotetext{
${ }^{10}$ It should be noted that this work history identifies the weeks in which women were employed rather than the weeks in which they were actually working. This is because the NLSY did not begin identifying unpaid maternity leave until the 1988 survey. To maintain consistency across survey years (between women who gave birth before and after the 1988 survey), I do not attempt to identify employed women on maternity leave. Thus, in my data, some women will be counted as employed when, in actuality, they were not working because they were on maternity leave. However, this should not be a substantial problem because most mothers only take a few weeks of maternity leave from work and the vast majority of this leave occurs after giving birth. For example, according to Klerman (1995), about 90 percent of NLSY mothers (who gave birth after 1987) take no more than 3 weeks of maternity leave prior to giving birth.
} 
Table 1 gives the sample means for each pregnancy employment variable, as well as these variables' means by trimester. ${ }^{11}$ As shown in this table, over 71 percent are employed while pregnant, though only 55.3 percent are employed during the third trimester. While the majority are employed, the proportion of hours worked averages only 0.532 , which is about 20 hours per week, and this proportion falls to 0.446 in the third trimester. Table 1 also shows the proportion of pregnant women who fall into each employment category (no work, greater than 0 and less than 20 weekly hours of work, 20 to 40 weekly hours of work, and 40 or more weekly hours of work) during the pregnancy and the trimesters. These variables show that, during the pregnancy, employed women are most likely to be in the 20 to 40 weekly hours of work category. Only about 24.6 percent of all mothers average 40 hours of work or more (overtime work) while pregnant. Over 36 percent average 40 hours or more during the first trimester, but this number falls to 25.7 percent in the third trimester.

In the 1988 and 1990 questionnaires, the NSLY surveys employed expectant mothers about job characteristics that might have pregnancy-relevant implications. ${ }^{12}$ Specifically, in these surveys, the NLSY asks pregnant women whether: (i) they are able to take a rest break at work, (ii) they work on an assembly line, (iii) they work with machinery that vibrates, (iv) they are required to do repetitive tasks, (v) they consider their work boring, (vi) their work is noisy, and (vii) their work occurs in an uncomfortably hot or cold area. The portion answering affirmatively to each characteristic is presented in table 2, which shows that some employed expectant mothers experience potentially harmful elements. For example, while pregnant, 5.9 work on an assembly line, 8.1 percent work with machinery that vibrates, 29.1 percent experience noise, 14.1 percent are uncomfortably hot, and 7.5 are uncomfortably cold. A substantial majority (70.1 percent) are able to take a rest break if fatigued.

\footnotetext{
${ }^{11}$ These trimesters are defined as the "first trimester" (weeks 0 to 14), the "second trimester" (weeks 14 to 30 ), and the "third trimester" (weeks 30 to the child's birth).

${ }^{12}$ Unfortunately, the NLSY did not collect this information in the other surveys. Consequently, information on job characteristics while pregnant is only identified for a portion (946) of the birthobservations included in my sample.
} 
In addition, the NLSY collects information on each respondent's children, including information on characteristics at birth. I use whether the infant was of low birth weight (below 2500 grams) as a proxy for health at birth. Babies may be of low birth weight because they are born preterm, because they grew slowly in utero, or because of a combination of both (Kline and Susser, 1989). To identify the ways in which pregnancy employment affects health at birth better, I also use the incidence of preterm birth (born with a gestation age less than 37 weeks) as a proxy for health at birth. The incidence of low birth weight and preterm birth are important measures of health at birth because they are shown to be significant predictors of infant mortality and morbidity, congenital abnormalities, and neurodevelopmental disorders (Koops, Morgan, and Battaglia, 1982; Institute of Medicine, 1985; McCormick, 1985; Kline and Susser, 1989; and Kiely and Susser, 1992). Table 3 shows that the sample incidence of low birth weight is 6.3 percent and the sample incidence of preterm birth is 6.0 percent.

Table 3 also identifies the incidence of low birth weight and preterm birth for the employment categories listed above (no work and weekly hours of work greater than 0 and less than 20 hours, from 20 to 40 hours, and 40 or more hours). Table 3 shows that during the pregnancy, the incidence of low birth weight is highest when pregnant women do not work, but the incidence of preterm birth is highest when pregnant women work from 20 to 40 hours per week. In general, these statistics do not suggest that employment while pregnant has a monotonic relationship with the incidence of low birth weight and preterm birth.

It is not clear that working during the pregnancy is correlated with health at birth. I next estimate the effects of pregnancy employment on health at birth controlling for a set of demographic variables using multivariate regression analysis. I use logit models for the probability of low birth weight and preterm birth. Each of the models contains a set of standard explanatory variables designed to control for exogenous characteristics of the woman, her child, and her community that might affect her infant's health at birth. These variables are exogenous in that they are not subject to change when the infant's health at birth is realized. I control for the 
child's gender and for the child's birth order. Race is controlled for with a dummy variable for being black and a dummy variable for being of Hispanic origin. I control for the woman's characteristics with variables measuring her age, body mass index (BMI), education level, and marital status. ${ }^{13}$ The theoretical model suggests that family income affects health at birth, so I include a measure of family income. My measure of family income (referred to as nonmaternal family income) includes wages and salary earned by the woman's spouse, his income from farms and/or businesses after expenses, alimony, child support, and income from savings accounts and assets, but it excludes any earnings from the woman's employment during the pregnancy. ${ }^{14}$ (As explained below, I explore the effects of including earnings from pregnancy employment in a separate set of models). I also control for region of residence with dummy variables for living in the northeast, south, and west. Residence in the midwest is the excluded category. I also include an urban dummy variable to control for whether the woman is from an urban or rural area. I include four additional variables to control for exogenous local health conditions: the countyspecific birth rate, the proportion of county births to women under the age of 20 , and the number of physicians and hospital beds in the county. Finally, I include year dummy variables for the calendar year of birth to control for time trends. Table 4 explains how each standard explanatory variable is measured, giving each variable's mean and standard deviation. Table 4 also gives these variables' means for women who did and did not work during the pregnancy. According to these statistics, women who work during the pregnancy are significantly more likely to be white, older, and married. Women who work during the pregnancy also have significantly fewer children (indicated by a lower birth order), more education, and less nonmaternal family income.

\footnotetext{
${ }^{13}$ BMI equals weight in kilograms divided by height in meters squared.

${ }^{14}$ Valid missing information is replaced with a zero. All income figures are deflated using the Consumer Price Index $(1987=100)$. Unfortunately, 534 observations that would otherwise be included in my analysis provide invalid responses to at least one of the questions used to identify family income (either nonmaternal family income or pregnancy earnings) and are consequently excluded.
} 
Models that include only the standard explanatory variables estimate the total effect of pregnancy employment. Conversely, models that include variables influenced by pregnancy employment show the partial effect of such employment because variables that change in response to a change in pregnancy employment are effectively held constant. To identify potential ways in which pregnancy employment affects health at birth, I include an additional set of variables that measure other pregnancy behaviors (that may be affected by pregnancy employment) in a portion of my models. First, to control for the possibility that alcohol consumption affects health at birth, I include a set of categorical variables measuring the amount of alcohol consumed during the pregnancy. Specifically, this set controls for whether the woman drank alcohol no more than once a month and for whether the woman drank alcohol more than once a month. The excluded category is no alcohol consumption. I also control for whether the woman smoked during the pregnancy with a set of categorical variables measuring the number of cigarettes smoked. In particular, this set controls for whether the woman smoked no more than one pack per day and for whether the woman smoked more than 1 pack per day. The excluded category is did not smoke. I control for whether the woman visited a physician during the pregnancy, as well as for the month of the pregnancy that the visit occurred. Further, I include a set of variables that describe a woman's other behaviors during the pregnancy. These variables include a "vitamin" variable that equals one if the woman took a vitamin supplement, a "calories" variable that equals one if the woman reduced her caloric intake, a "salt" variable that equals one if the woman reduced her salt intake, and a "diuretic" variable that equals one if the woman took a diuretic. Finally, I control for whether the expectant mother took a sonogram/ultrasound and an amniocentesis. Again, models that include variables measuring pregnancy behaviors will only show the partial effect of pregnancy employment because such employment may affect health at birth through these channels.

Table 4 gives the pregnancy behavior variables' means and standard deviations, as well as these means for women who did and did not work during the pregnancy. For example, these 
statistics show that the majority of women do not drink alcohol or smoke cigarettes while pregnant. Almost all women visit a physician (by the date of birth), and this visit occurs on average during the third month of the pregnancy. Of particular note, those who work during the pregnancy are generally more likely to exhibit healthy pregnancy behaviors. In particular, women who work while pregnant are less likely to smoke cigarettes and more likely to visit a physician earlier in the pregnancy, to take a vitamin supplement, and to reduce salt intake. The primary exception is alcohol consumption: women who work during the pregnancy are significantly more likely to drink.

Another variable that will be influenced by pregnancy employment is the woman's earnings from employment while pregnant. Specifically, family earnings will increase with pregnancy employment. And, as described in the theory section, family income will have an effect on health at birth if greater income increases the amount of money that can be spent on inputs that contribute to the infant's health. For comparison purposes, I include a variable measuring the woman's pregnancy earnings in a separate portion of the models to see how the effect of pregnancy employment changes. As before, models that include pregnancy earnings will only show the partial effect of pregnancy employment because the effect of such employment will be found holding total family income constant. When pregnancy earnings is included, it consists of the wages and salary earned by the mother, as well as any income from a farm and/or business after expenses. ${ }^{15}$ According to table 4, pregnancy earnings average about $\$ 7,253$ (\$9,968 for women who worked while pregnant).

Further, I include a preterm birth indicator as a control variable in some of my low birth weight models because pregnancy employment may affect birth weight by affecting the length of gestation. Models that control for preterm birth essentially show the effect of pregnancy

\footnotetext{
${ }^{15}$ All income figures are deflated using the Consumer Price Index $(1987=100)$. Observations with invalid missing income information are excluded from the analysis.
} 
employment among women with the same pregnancy length. This reveals whether pregnancy employment's effects operate by affecting gestation length and/or growth in utero.

Ideally, the explanatory variables would include all factors that affect health at birth. However, if some of these factors are unobserved (or unmeasurable) to the researcher, then the error term will capture these unobserved variables. Unobserved heterogeneity will produce biased results if the error term and any included explanatory variable are correlated with the same unobserved characteristics. This will be true of the pregnancy employment variables if women who work while pregnant systematically differ from women who do not work in ways that are unobserved to the researcher. For example, suppose that women who work have systematically different traits that affect health at birth. ${ }^{16}$ If these traits are unobserved, then the error term in the health at birth equation will be correlated with pregnancy employment, which is an explanatory variable in that equation. If this is the case, then pregnancy employment and health at birth are correlated with the same unobserved traits, which will produce bias results. If these unobserved factors are not adequately controlled, then employment while pregnant may spuriously appear to affect child health when, in fact, there may not be a causal relationship.

I attempt to control for the potentially biasing effects of unobserved heterogeneity using a fixed effects estimator. I assume that the effects of pregnancy employment on infant health can be estimated from the following model:

$$
\mathrm{Y}_{\mathrm{ic}}=\beta \mathbf{X}_{\mathrm{ic}}+v_{\mathrm{i}}+\varepsilon_{\mathrm{ic}}
$$

where $\mathrm{Y}$ is a measure of infant health, $\mathbf{X}$ is a vector of explanatory variables that includes measures of pregnancy employment, $v_{\mathrm{i}}$ is a woman-specific factor representing woman i's unobserved characteristics, and $\varepsilon$ is the error term for child $\mathrm{c}$ and mother $\mathrm{i}$. In this context, if correlation between $\mathbf{X}$ and $v_{\mathrm{i}}$ exists and if the heterogeneity component $\left(v_{\mathrm{i}}\right)$ is unobserved to the

\footnotetext{
${ }^{16}$ Rosenzweig and Schultz (1982, 1983a, 1983b) argue that during the pregnancy parents have expectations about "baseline" infant health that are unobserved to the researcher, and these expectations may alter pregnancy behaviors such as whether the expectant mother smokes or is employed. Joyce (1987) notes that it is quite possible for such expectations to be formed from ultrasounds or amniocenteses.
} 
researcher, then estimates will be biased. To control for this potential source of bias, the fixedeffects technique uses cases where the woman gives birth to more than one child, differencing infant health measures between siblings from the same mother,

$$
\mathrm{Y}_{\mathrm{ic}}-\mathrm{Y}_{\mathrm{js}}=\beta\left(\mathbf{X}_{\mathrm{ic}}-\mathbf{X}_{\mathrm{js}}\right)+\left(v_{\mathrm{ic}}-v_{\mathrm{is}}\right)+\left(\varepsilon_{\mathrm{ic}}-\varepsilon_{\mathrm{is}}\right) \quad \forall \mathrm{s},
$$

for mother i, child c, and child sibling s (with Y, X, $v$, and $\varepsilon$ as define above). ${ }^{17,18}$ If the unobserved component $\left(v_{\mathrm{i}}\right)$ is intertemporally fixed for mother $\mathrm{i}$, then $v_{\mathrm{ic}}=v_{\text {is }}$ and unbiased estimates are obtained. Of course, if the woman's unobserved component is not constant between children, then the estimates may still be biased. ${ }^{19}$

Another potential source of bias is sample selection, which would exist if pregnancy employment affects the probability of delivering a live birth. For example, if women who work while pregnant are more likely to give birth to a stillborn, then the effects of pregnancy employment will be biased because my sample of live births will contain a disproportionately large number of women who did not work during the pregnancy. Fortunately, any effects from

\footnotetext{
${ }^{17}$ If pregnancy employment does not vary between siblings, then the fixed effects models will produce statistically insignificant results. Fortunately, of the 1212 sibling-pairs in my fixed effects models, 273 (about 22.5 percent) have different values for the pregnancy employment dummy variable (i.e., the expectant mother was employed during one pregnancy but not the other), and the portion of hours employed during the pregnancy varies for over 72 percent of the sibling-pairs. Further, for almost 50 percent of the sibling-pairs, the mother switches between pregnancy employment categories (zero hours, greater than 0 and less than 20 hours, from 20 to 40 hours, 40 or more hours) between sibling pregnancies.

${ }^{18}$ The fixed effects estimator is subject to potential sample selection bias because only women with at least two children are used in the estimation. However, if the unobserved determinants of fertility are constant over time (or within families/for the same woman), then these unobserved determinants are effectively "differenced out" in fixed effects models. This is assumed by others who examine child health using fixed effects estimators (Rosenzweig and Wolpin, 1988).

${ }^{19}$ My fixed effects models are similar to Rosenzweig and Wolpin's $(1988,1991)$ fixed effects models that control for family-specific unobserved heterogeneity (heterogeneity that is constant among siblings within a family). However, Rosenzweig and Wolpin (1988) also estimate models that control for child-specific unobserved heterogeneity (heterogeneity within the family) using an instrumental variables (IV) procedure with their fixed effects estimator. In particular, they use IV to obtain predicted values of potentially endogenous variables, and they include these predicted values in their fixed effects models. I attempted a version of their IV-fixed effects model, but the instruments were too weak to produce meaningful results. This is a problem in the Rosenzweig and Wolpin (1988) study as well.
} 
this potential source of bias should be small because my estimates indicate that only about 1 percent of NLSY pregnancies result in a stillborn birth. ${ }^{20}$

\section{Results}

First, I examine the probability of low birth weight and preterm birth, and I present the pregnancy employment variables' results from these models in tables 5 and 6 , respectively. ${ }^{21}$ I also estimate models that separately examine the effects of pregnancy employment by trimester. These results are presented in table 7 . Then, I re-estimate the low birth weight models controlling for preterm birth. Key results from these models are presented in table 8 . Next, to examine the potential for unobserved heterogeneity bias, I re-estimate the models on a sub-sample of women who were employed during the year preceding their pregnancy and then I re-estimate the models examining the effects of employment during the year prior to the pregnancy. Selected results from these models are presented in table 9. Finally, I estimate sibling fixed effects models to explore the potential for unobserved heterogeneity bias further. The pregnancy employment results from the fixed effects models are displayed in table 10. The appendix table presents sample results for selected other covariates.

\section{$\underline{\text { Low Birth Weight }}$}

I first examine the effects of pregnancy employment with a variable that equals 1 if the woman was employed during the pregnancy (model 1). Specification 1 identifies pregnancy employment's total effect, showing that being employed during the pregnancy has a marginally statistically significant negative effect on the probability of low birth weight (specification 1). In specification 1, pregnancy employment decreases this probability from 7.4 to 5.8 percent, which

\footnotetext{
${ }^{20}$ Others (Currie et al., 1996) have found that excluding fetal losses from the sample has virtually no effect in models of health at birth.

${ }^{21}$ I also estimate a birth weight ordered logit with three possible outcomes: severely low birth weight $(<1500$ grams), moderately low birth weight (1500-2500 grams), and normal birthweight (2500 grams or more). However, the coefficients are virtually the same as those for the dichotomous logit (reported in the paper). The reason for this is that there are very few observations in the "severely low birth weight" category. In particular, of the 3,546 observations in my birth weight models, 3,321 are of normal birth weight, 206 are moderately low, and 19 are severely low.
} 
is a reduction of about 21.6 percent. The beneficial effect of pregnancy employment is virtually the same when I control for other pregnancy behaviors (specification 2), so little of pregnancy employment's effect appears to operate through these channels. However, the statistically significant beneficial effect of pregnancy employment is eliminated when pregnancy earnings is added (specification 3), suggesting that pregnancy employment at least partially affects the incidence of low birth weight by increasing family income.

Next, I specify pregnancy employment to equal the proportion of hours worked, where "hours worked" is the average number of hours worked in each week of the pregnancy (divided by the number of weeks). Model 2 in table 5 shows that average weekly hours worked has a marginally significant negative effect on the probability of low birth weight in specification 1. Switching from no work to full time work ( 40 hours per week) changes this probability from 7.3 to 5.4 percent, which is a 26.0 percent reduction. This effect is reduced in magnitude when controlling for other pregnancy behaviors and becomes statistically insignificant when controlling for pregnancy earnings. Thus, it appears that other pregnancy behaviors and pregnancy earnings explain a portion of pregnancy employment's beneficial effects.

I next estimate a model (model 3) that allows for non-linear effects. I do this by including the pregnancy employment variable and the proportion of hours worked variable. ${ }^{22}$ The three specifications' results are similar, showing that pregnancy employment reduces the incidence of low birth weight. However, the pregnancy employment variables are not statistically significant in these specifications.

Finally, I specify pregnancy employment with the categorical variables (model 4). These categories include working greater than 0 and less than 20 hours, from 20 to 40 hours, and 40 or more hours (with no work being the excluded category). Working 40 or more hours per week significantly decreases the incidence of low birth weight for some specifications. In specification

\footnotetext{
${ }^{22}$ I also examine non-linear trends by including the "portion of hours worked" variable and its squared value in a model. However, I do not report these results because they are very similar to those reported for model 3 .
} 
1, working 40 or more hours reduces this probability from 7.0 to 4.1 percent, which is a 41.4 percent change. This beneficial effect is not particularly reduced when I control for pregnancy behaviors. However, when I control for pregnancy earnings, any beneficial effects of working are no longer statistically significant at the 95 percent confidence level. It appears the significant beneficial effect of working 40 or more hours per week is at least partially due to increased family income via pregnancy earnings.

\section{Preterm Birth}

My first model in table 6 measures employment with a variable that equals 1 if the woman was employed during the pregnancy. Specification 1 shows that being employed during the pregnancy has a statistically insignificant effect on the incidence of preterm birth. When variables measuring pregnancy behaviors are added (specification 2), pregnancy employment's coefficient remains statistically insignificant. Adding controls for pregnancy earnings (specification 3) also leaves the pregnancy employment coefficient statistically insignificant. When I measure pregnancy employment with the portion of hours worked during the pregnancy (model 2), the effects remain statistically insignificant in each specification. To examine potential non-linear effects, I next estimate a model (model 3) that includes both the pregnancy dummy variable as well as the continuous variable measuring the proportion of hours worked. However, the pregnancy employment variables remain statistically insignificant.

In model 4, I measure pregnancy employment with categorical variables as defined above to allow more flexibility to fit the data. Working greater than 0 and less than 20 hours per week significantly reduces the incidence of preterm birth in each specification at the 90 percent confidence level. For example, in specification 1, this category of pregnancy employment decreases preterm births from 6.4 to 4.1 percent, which about a 35.9 percent change. The other employment category variables do not have effects that are significantly different than zero. When controlling for other pregnancy behaviors and pregnancy earnings, the pregnancy 
employment coefficients are substantively unchanged. It is interesting to note that, relative to not working, none of the categorical variables have statistically significant, harmful effects.

\section{The Effects of the Timing of Pregnancy Employment}

Next, I examine the effects of the timing of pregnancy employment. I do this by reestimating the models with separate pregnancy employment variables for each trimester. Results from specification 1 (not including other pregnancy behavior and pregnancy earnings variables) are presented in table 7. Results from specifications 2 and 3 follow a similar pattern to that exhibited above and are not reported. Many of the effects are statistically insignificant, probably due to multicolinearity across the three trimesters. That is, pregnancy employment across the three trimesters is quite correlated, and different effects across trimesters are identified by relatively infrequent changes in pregnancy employment. However, where statistically significant, it appears that pregnancy employment in the third trimester is most likely to have beneficial effects on low birth weight and preterm birth. Actually, there is some evidence that pregnancy employment from the second trimester has harmful effects, but first trimester pregnancy employment almost always has statistically insignificant effects.

\section{Other Pregnancy Employment Results}

The results in tables 5 and 6 indicate that pregnancy employment has beneficial effects on the incidence of low birth weight and on the incidence of preterm birth. If indeed pregnancy employment decreases the incidence of preterm birth, then it is not clear whether positive effects on the incidence of low birth weight are by influencing gestation length or utero growth. To investigate this further, I re-estimate the low birth weight models from table 5 controlling for preterm birth. The key results are presented in table 8 . These results essentially examine the effect of pregnancy employment on low birth weight holding gestation age constant. Table 8's results show that pregnancy employment still has beneficial effects in some of the model specifications. For example, in model 2 (specification 1), switching from no work hours to full time work reduces the incidence of low birth weight from 7.6 to 5.1 percent, which is a 32.8 
percent change (compared to a 26.0 percent change in model 2 from table 4); in model 4, switching from no work hours to 40 or more hours per week reduces the low birth weight incidence from 7.0 to 4.1 percent, which is a 41.4 percent change (compared to a 41.4 percent change in model 4 from table 4). The pregnancy employment coefficients again tend to become less statistically significant when controlling for pregnancy earnings. It is also interesting to note that preterm birth significantly increases the incidence of low birth weight in each model. ${ }^{23}$ Thus, pregnancy employment's beneficial effects on the incidence of low birth weight appear to operate through utero growth.

In addition, I re-estimate the models identifying the effects of job characteristics (characteristics as listed in table 2) using the 1988/1990-questionnaire subsample for whom this information is available. In some of these models, I include the job characteristics variables (8 dummy variables) instead of the pregnancy employment variable(s); in other models, I include both the job characteristics variables and the pregnancy employment variable(s). In both types of models (results not shown), the job characteristics variables have statistically insignificant effects, though pregnancy employment, when included, continues to have beneficial effects similar to those described above. Thus, results continue to indicate that pregnancy employment has no harmful effects on birth outcomes. Perhaps pregnancy employment does not have harmful effects because potentially harmful elements experienced while employed do not have effects.

Thus far, the results have indicated that, if anything, pregnancy employment reduces the probability of low birth weight and preterm birth. However, it is not clear why employment has beneficial effects on these birth outcomes. Theoretically, pregnancy employment could influence other pregnancy behaviors and increase family. However, controlling for a set of pregnancy behaviors explains little of pregnancy employment's beneficial effects. Controlling for

\footnotetext{
${ }^{23}$ Descriptive statistics indicate that 50.6 percent of low birth weight births are preterm and that 53.7 percent of preterm births are of low birth weight.
} 
pregnancy earnings tends to reduce the statistical significance of the pregnancy employment variables, though statistically beneficial effects occasionally remain in some of the models. ${ }^{24}$

Perhaps pregnancy employment's effects are due to unobserved characteristics that are correlated with birth outcomes and pregnancy employment. That is, perhaps women who are attached to the labor force systematically differ from those who are not. To investigate this, I examine a sub-sample of women who are employed during at least a portion of the year preceding their pregnancy. This sample of "working women" should be more homogeneous, reducing the potential for unobserved heterogeneity bias. Results (not shown) reveal that in this sub-sample, the effects of pregnancy employment are statistically insignificant in almost every instance. Thus, once the distinction between employed and nonemployed women is made, the amount worked by employed women does not affect the incidence of low birth weight or preterm birth. This raises the possibility that employed and nonemployed women systematically differ in unobserved ways, and pregnancy employment may be serving as a proxy for these unobserved characteristics.

To explore this further, I next re-estimate the models examining the effects of prepregnancy employment instead of pregnancy employment. This is another way to test for unobserved heterogeneity bias because pre-pregnancy employment should have no effect on birth outcomes since such employment occurs, by definition, prior to the pregnancy. If pre-pregnancy employment has significant effects, then this would be further evidence that employment variables are picking up the effects of unobserved factors. Thus, I construct employment variables as before but I examine the pre-pregnancy year instead of covering the pregnancy period. Then, I re-estimate the models using the pre-pregnancy employment variables instead of

\footnotetext{
${ }^{24}$ I also re-estimate my models on a low-income subsample. This subsample consists of expectant mothers whose household income would have been below the poverty line if the expectant mother did not work. Pregnancy employment consistently has larger beneficial effects on low birth weight in these models than in those for the full sample. Further, including pregnancy earnings in these models noticeably reduces the statistical significance of the pregnancy employment variable(s). This suggests that increased family income via pregnancy employment has a greater impact in low-income households. Thus, there is some evidence that pregnancy employment is more beneficial for low-income households. However, in the preterm birth models, the effects of pregnancy employment are no more beneficial for the low-income subsample than in the full sample.
} 
the pregnancy employment variables. These results are presented in table 9 and are from specification 1, which estimates the total effect of hours worked during the pregnancy. I do not report results from specifications 2 and 3 (which control for other pregnancy behaviors and pregnancy earnings) because they are similar to those from specification 1.

Table 9 shows that the results using the pre-pregnancy employment variables are similar to those using the pregnancy employment variables: pre-pregnancy employment has statistically significant, beneficial effects on the incidence of low birth weight and on the incidence of preterm birth. For example, pre-pregnancy employment significantly decreases the probability of low birth weight and preterm birth (the pregnancy employment dummy variable in models 1 and 3), as do a couple of the employment category variables (model 4). Perhaps this is an indication that significant effects in the original OLS models represent unobserved heterogeneity rather than causal effects: again, any effect of pre-pregnancy employment should have no causal effect on the birth outcomes by definition.

Conversely, one might argue that pre-pregnancy employment is a proxy for pregnancy employment (since they are highly correlated), and the positive effects of pre-pregnancy employment reflect pregnancy employment's positive effects found in the initial set of OLS models. To examine this, I next re-estimate the models including both the pre-pregnancy and the pregnancy employment variables. Results (not shown) reveal that pre-pregnancy employment and pregnancy employment simultaneously have significant, beneficial effects in some of the models. I again conclude that the measures of employment may be serving as proxies for unobserved characteristics since the pre-pregnancy employment variables continue to affect the birth outcomes significantly.

To explore further the potential effects of unobserved heterogeneity bias, I re-estimate the models using the sibling fixed effects technique. I report the results from specification 1 (which shows the total effect of pregnancy employment) in table 10. Results (not shown) from specifications 2 and 3 (with pregnancy behavior and pregnancy earnings variables) are similar to 
those from specification 1 . When using the sibling fixed effects technique, the effect of pregnancy employment is no longer statistically significant in any of the models. This further suggests that the beneficial effects of pregnancy employment found in the OLS models are due to unobserved heterogeneity. ${ }^{25}$

\section{The Effects of Other Covariates}

The effects of other covariates, presented in the appendix table, are also of interest. In particular, while alcohol consumption does not have detrimental effects, cigarette smoking significantly increases the probability of low birth weight. This is typical of that found in the literature (for example, see Rosenzweig and Schultz, 1983b; Corman, Joyce, and Grossman, 1987; and Rosenzweig and Wolpin, 1991). However, cigarette smoking does not significantly affect the incidence of preterm birth. Other pregnancy behaviors do not significantly affect the incidence of low birth weight or preterm birth, though taking a sonogram or amniocentesis is associated with a greater incidence of low birth weight and preterm birth.

Demographic covariates from the OLS models show that males are significantly less likely to be of low birth weight. Body mass index significantly reduces the incidence of low birth weight as does marriage. Being married also is significantly associated with fewer preterm births. The incidence of preterm birth is also significantly affected by area of residence (living in an urban area significantly increases preterm births). There is also some evidence that the variables

\footnotetext{
${ }^{25}$ Since the fixed effects model uses a sample (of siblings) that is smaller than the OLS sample (the sibling pairs used in the low birth weight and preterm birth fixed effects models are generated from 1,839 observations with a corresponding sibling versus 3,546 observations in the birth weight and low birth weight OLS models), it might be most appropriate to compare the fixed effects results with OLS results using the same sample used in the fixed effects model. Such a comparison would show the direction of unobserved heterogeneity bias, if any. It might not be appropriate to estimate the direction of such bias comparing fixed effects results from the smaller sample with OLS results from the full sample. However, OLS results with the smaller fixed effects sample are very similar to OLS results with the full sample, though standard errors from the fixed effects sample tend to be somewhat larger. Thus, I conclude that the OLS results with the full sample differ from the fixed effects results because of the way they treat individual-specific unobservables rather than the way the sample is limited when the fixed effects models are estimated. For brevity, I do not report OLS results using the fixed effects sample. However, these results are available from the author upon request.
} 
measuring economic conditions have significant effects. For example, the portion of births to women under 20 significantly increases the incidence of low birth weight and preterm birth.

\section{Discussion and Conclusion}

Initial results with the full sample seem to suggest that pregnancy employment's total effect on the incidence of low birth weight and preterm birth is beneficial, with this effect being statistically significant in many of the models. This analysis attempts to identify explanations for these beneficial effects by examining various mediating factors (such as other pregnancy behaviors and pregnancy earnings). Controlling for other pregnancy behaviors has virtually no effect on the pregnancy employment coefficients. Controlling for pregnancy earnings does reduce the statistical significance of the pregnancy employment variables, causing them to become insignificant in some of the models. Results also suggest that pregnancy employment is most likely to have a beneficial effect in the third trimester. Further, results suggest that pregnancy employment does not have an indirect effect on low birth weight via the incidence of preterm birth; instead, its effects are through utero growth.

Though initial models with the full sample indicate beneficial effects of pregnancy employment, additional results suggest that this may be due to unobserved heterogeneity bias. When examining a more homogeneous sub-sample of employed women, hours worked during the pregnancy has statistically insignificant effects. At a minimum, this shows that the effect of working additional hours in the marketplace is insignificant when controlling for employment status. Further, pre-pregnancy employment, which should not affect birth outcomes, has significant, beneficial effects in some of the models, and pregnancy employment has statistically insignificant effects in fixed effects models. Thus, I conclude that though pregnancy employment may be correlated with the incidence of low birth weight and preterm birth, these relationships are not causal.

My results are important because they illustrate whether the increased labor force participation rate of women affects health at birth. It is interesting to note that pregnancy 
employment does not have detrimental health effects in any of the models. Thus, taking time off from work would not appear to offer any health benefits to infants, and the increased labor force participation rate of women would not seem to be of great concern to health at birth. 


\section{References}

Ahlfors, K., S. Harris, S. Ivarsson, and L. Svanberg. "Secondary Maternal Cytomegalovirus Infection Causing Symptomatic Congenital Infection," New England Journal of Medicine, " 305 (5): 284.

Baum, Charles L. (2003). "Does Early Maternal Employment Harm Child Development? An Analysis of the Potential Benefits of Leave Taking." Journal of Labor Economics 21 (2): 409448.

Becker, Gary S. (1965). "A Theory of the Allocation of Time," Economic Journal, 75: 493-517.

Becker, Gary S. (1981). A Treatise on the Family. Cambridge, Mass.: Harvard University Press.

Becker, Gary S., and Tomes, N. (1986). "Human Capital and the Rise and Fall of Families," Journal of Labor Economics, 4, S1-S39.

Blau, Francine D., and Grossberg, Adam J. (1992). "Maternal Labor Supply and Children's Cognitive Development," The Review of Economics and Statistics, 74, 474-481.

Bureau of Labor Statistics. (2000). "Working in the $21^{\text {st }}$ Century." http://www.bls.gov/opub/working/home.htm.

Brunell, P. (1983). "Fetal and Neonatal Varicella Zoster Infections," Seminars in Perinatology, 7 (1): 47-56.

Colie, C. (1993). "Preterm Labor and Delivery in Working Women," Seminars in Perinatology, 17 (1): $37-44$.

Corman, Hope, Theodore J. Joyce, and Michael Grossman. (1987). "Birth Outcome Production Function in the United States," The Journal of Human Resources 22 (3): 339-360.

Cornelius, Marie D., Paul M. Taylor, Diklah Geva, Nancy L. Day. (1995). "Prenatal tobacco and marijuana use among adolescents: effects on offspring gestational age, growth, and morphology." Pediatrics, 95 (5): 738-744.

Cramer, James C. (1995). "Racial and Ethnic Differences in Birthweight: The Role of Income and Financial Assistance," 32 (2): 231-247.

Currie, Janet and Nancy Cole. (1993). "Welfare and Child Health: The Link Between AFDC Participation and Birth Weight," American Economic Review 83 (4): 971-985.

Currie, Janet and Jeffrey Grogger. (2002). "Medicaid Expansions and Welfare Contractions: Offsetting Effects on Prenatal Care and Infant Health?” Journal of Health Economics, 21 (2): 313-335.

Currie, Janet, Lucia Nixon, and Nancy Cole. (1996). "Restrictions on Medicaid Funding of Abortion," The Journal of Human Resources, 31 (1): 159-188. 
Desai, Sonalde, Chase-Lansdale, P. Lindsay, \& Michael, Robert T. (1989). "Mother or Market? Effects of Maternal Employment on Intellectual Ability of 4-Year-Old Children," Demography, 26 (4), 545-561.

Dunn, K., H. Yoshimaru, M. Otake, J. Annegers, and W. Schull. (1990). "Prenatal Exposure to Ionizing Radiation and Subsequent Development of Seizures," American Journal of Epidemiology, 131 (1): 114-123.

Egbuonu, L. and B. Starfield. (1982). "Child Health and Social Status," Pediatrics, 69, 550-557.

Emhart, C. (1992). "A Critical Review of Low-Level Prenatal Lead Exposure in the Human: 2. Effects on the Developing Child," Reproductive Toxicology, 6 (1): 21-40.

Feinberg, Jason S. "Pregnant Workers: A Physician's Guide to Assessing Safe Employment," The Western Journal of Medicine, 168 (2): 86-93.

Frank, Richard G., Donna M. Strobino, David S. Salkever, and Catherine A. Jackson. (1992). "Updated Estimates of the Impact of Prenatal Care on Birthweight Outcomes by Race," The Journal of Human Resources, 27 (4): 629-642.

Frisbie, W. Parker, Douglas Forbes, and Starling G. Pullum. (1996). "Compromised Birth Outcomes and Infant Mortality Among Racial and Ethnic Groups," Demography 33 (4): 469-481.

Grossman, Michael. (1972). The Demand for Health: A Theoretical and Empirical Investigation. New York: Columbia University Press.

Grossman, Michael. (2001). "The Economics of Substance Use and Abuse: The Role of Price." In Economic Analysis of Substance Use and Abuse: The Experience of Developed Countries and Lessons for Developing Countries, edited by Michael Grossman and Chee-Ruey Hsieh.

Cheltenham, U.K.: Edward Elgar Limited: 1-30.

Grossman, Michael, and Theodore J. Joyce. (1990). "Unobservables, Pregnancy Resolutions, and Birth Weight Production Functions in New York City," Journal of Political Economy 98 (5): 983-1007.

Guo, Guang and Kathleen Mullan Harris. (2000). "The Mechanisms Mediating the Effects of Poverty on Children's Intellectual Development," Demography 37 (4), 431-447.

Hill, M. Anne, and O'Neill, June E. (1994). "Family Endowments and the Achievement of Young Children with Special Reference to the Underclass," The Journal of Human Resources, 29 (4), 1064-1101.

Hueston, William J., Arch G. Mainous III, and J. Brad Farrell. (1994). "A cost-benefit analysis of smoking cessation programs during the first trimester of pregnancy for the prevention of low birthweight." Journal of Family Practice, 39 (4): 353-358.

Institute of Medicine. (1985). Preventing Low Birth Weight. Washington, D.C: National Academy Press.

Jones, C.L. and R.E. Lopez. (1990). "Drug Abuse and Pregnancy," in New Perspectives on Prenatal Care (eds. I.R. Merkatz and J.E. Thompson). New York: Elsevier. 
Joyce, Theodore J. (1987). "The Impact of Induced Abortion on Black and White Birth Outcomes in the United States," Demography 24 (2): 229-244.

Joyce, Theodore J. (1994). "Self-Selection, Prenatal Care, and Birthweight Among Blacks, Whites, and Hispanics in New York City," The Journal of Human Resources, 29 (3): 762-794.

Joyce, Theodore J., Andrew D. Racine, and Naci Mocan. (1992). "The Consequences and Costs of Maternal Substance Abuse in New York City," The Journal of Health Economics, 11 (3): 297314.

Kaestner, Robert, Theodore Joyce, and Hassan Wehbeh. (1996). "The Effect of Maternal Drug Use on Birth Weight: Measurement Error in Binary Variables," Economic Inquiry, 34 (4): 617629.

Kiely, J. L., and M. Susser. (1992). "Preterm Birth, Intrauterine Growth Retardation, and Perinatal Mortality." American Journal of Public Health, 82: 343-345.

Klebanoff, M., P. Shiono, and G. Rheads. (1990). "Outcome of Pregnancy in National Sample of Resident Physicians," New England Journal of Medicine, 323 (15): 1040-1045.

Klerman, Jacob Alex (1995). "Characterizing Leave for Maternity," unpublished manuscript, The Economics and Statistics Department, The RAND Corporation.

Klerman, Jacob Alex, and Leibowitz, Arleen. (1990). "Child Care and Women's Return to Work After Childbirth," American Economic Review, 80 (2), 284-288.

Klerman, L.V. (1991). "The Health of Poor Children: Problems and Programs," in Children in Poverty: Child Development and Public Policy (eds. A.C. Huston) Cambridge, UK: Cambridge University Press.

Kline, J., Z. Stein, and M. Susser. (1989). Conception to Birth: Epidemiology of Prenatal Development. New York: Oxford University Press.

Koops. B. L., L. J. Morgan, and F. C. Battaglia. (1982). "Neonatal Mortality Risk in Relation to Birth Weight and Gestational Age: Update," Journal of Pediatrics, 101: 969-977.

Lightwood, James M., Ciaran S. Phibbs, and Stanton A. Glantz. (1999). "Short-term Health and Economic Benefits of Smoking Cessation: Low Birth Weight.” Pediatrics, 104 (6): 1312.

Liu, Gordon G. (1998). "Birth Outcomes and the Effectiveness of Prenatal Care," Health Services Research, 32 (6): 805-823.

Luke, Barbara, Nicole Mamelle, Louis Keith, Francoise Munoz, John Minogue, Emile Papiernik, and Timothy R.B. Johnson. (1995). "The Association Between Occupational Factor and Preterm Birth: A United States Nurses' Study," American Journal of Obstetrics and Gynecology, 173 (3): 849-862.

Mamelle, N., B. Lauman, and P. Lazar. (1984). "Prematurity and Occupational Activity During Pregnancy," American Journal of Epidemiology, 119 (3): 309-322. 
McCormick, M. C. (1985). "The Contribution of Low Birth Weight to Infant Mortality and Childhood Mortality." New England Journal of Medicine, 312: 82-90.

McMichael, A., G. Vimpani, E. Robertson, P. Baghurst, and P. Clark. (1986). "The Port Pine Cohort Study: Maternal Blood Lead and Pregnancy Outcome," Journal of Epidemiology and Community Health, 40 (1): 18-25.

Mocan, Naci H. and Kudret Topyan. (1995). "Illegal Drug Use and Health: Analysis and Projections of New York City Birth Outcomes Using a Kalman Filter Model," Southern Economic Journal, 62 (1): 164-182.

Mott, Frank L. (1991). "Developmental Effects of Infant Care: The Mediating Role of Gender and Health,” Journal of Social Issues, 47 (2), 139-158.

Pass, R., A. August, M. Duvorsky, and D. Reynolds. (1982). "Cytomegalovirus Infection in Day Care Cetners," New England Journal of Medicine, 307: 477-479.

Pless, I.B., R. Verreault, and S. Tenina. (1989). "A Case-Control Study of Pedestrian and Bicyclist Injuries in Childhood," American Journal of Public Health, 79, 995-998;

Preblud, S., D. Bregman, and L. Vemon. (1985). "Deaths from Varicella in Infants," Pediatric Infectious Disease, 4 (5): 503-507.

Pritchett, Lant and Lawrence H. Summers. (1996). "Wealthier is Healthier," The Journal of Human Resources, 31 (4): 841-868.

Rodis, J., D. Quinn, W. Gary, L. Anderson, S. Rosengren, S. L. Cartter, W. Campbell, and A. Vintzileos. (1990). "Management and Outcomes of Pregnancies Complicated by Human B 19 Parvovirus Infections: A Prospective Study," American Journal of Obstetrics and Gynecology, 163 (4): 1168-1171.

Rosensweig, Mark R. and T. Paul Schultz. (1982). "Market Opportunities, Genetic Endowments, and Intrafamily Resource Distribution: Child Survival in Rural India," American Economic Review 72 (4): 803-815.

Rosenzweig, Mark R. and T. Paul Schultz. (1983a). "Estimating a Household Production Function: Heterogeneity, the Demand for Health Inputs, and Their Effects on Birth Weight," Journal of Political Economy 91 (5): 723-746.

Rosenzweig, Mark R. and T. Paul Schultz. (1983b). "Consumer Demand and Household Production: The Relationship between Fertility and Child Mortality," American Economic Review 73 (2): $38-42$.

Rosenzweig, Mark R. and Kenneth I. Wolpin. (1988). "Heterogeneity, Intrafamily Distribution, and Child Health," The Journal of Human Resources 23 (4): 437-461.

Rosenzweig, Mark R. and Kenneth I. Wolpin. (1991). "Inequality at Birth," Journal of Econometrics, 50 (1-2): 205-228.

Smolensky, Eugene, and Jennifer Appleton Gootman. (2003). Working Families and Growing Kids: Caring for Children and Adolescents. Washington, D.C.: The National Academy Press. 
Stockwell, E.G., D.A. Swanson, and J.W. Wicks. (1988). "Economic Status Differences in Infant Mortality by Cause of Death," Public Health Reports, 103, 135-142.

Teitelman, M., C. Welch, K. Hellenbrand, and M. Bracken. (1990). "Effect of Maternal Work Activity on Preterm Birth and Low Birth Weight," American Journal of Epidemiology, 131 (1): 104-113.

Tomes, N. (1981). "The Family, Inheritance, and the Intergenerational Transmission of Inequality," The Journal of Political Economy, 89 (5), 928-958.

Warner, Geoffrey L. (1995). "Prenatal Care Demand and Birthweight Production of Black Mothers," American Economic Review, 85 (2): 132-137. 
Table 1: Descriptive Statistics of the Pregnancy Employment Variables

\section{Employed}

During Pregnancy

During First Trimester

During Second Trimester

During Third Trimester

Proportion of Hours Worked

During Pregnancy

During First Trimester

During Second Trimester

During Third Trimester

Proportion of Hours Worked -- Pregnancy

No Work

Greater than 0 and less than 20 Hours per Week

From 20 to 40 Hours per Week

40 or more Hours per Week

\section{Proportion of Hours Worked -- First Trimester}

No Work

Greater than 0 and less than 20 Hours per Week

From 20 to 40 Hours per Week

40 or more Hours per Week

\section{Means}

0.711

0.696

0.637

0.553

0.532

0.585

0.529

0.446

0.289

0.190

0.275

0.246

0.304

0.134

0.199

0.364

0.363

0.128

0.182

0.327

0.447

0.124

0.172

0.257
Standard Deviation

0.453

0.460

0.481

0.497

0.451

0.473

0.478

0.471

0.453

0.393

0.447

0.431

0.460

0.341

0.399

0.481

0.481

0.334

0.386

0.469

Proportion of Hours Worked -- Third Trimester

No Work

0.497

Greater than 0 and less than 20 Hours per Week

0.329

From 20 to 40 Hours per Week

0.378

40 or more Hours per Week

0.437 
Table 2: Descriptive Statistics - Job Characteristics of Employed Expectant Mothers

\begin{tabular}{lcc}
\hline Job Characteristic: & Mean & Std. Dev. \\
Able to Take a Rest Break & 0.701 & 0.457 \\
Work on an Assembly Line & 0.059 & 0.236 \\
Work with Machinery that Vibrates & 0.081 & 0.273 \\
Required to Do Repetitive Tasks & 0.361 & 0.480 \\
Consider your Work Boring & 0.144 & 0.351 \\
Noise at Work & 0.291 & 0.454 \\
Work in an Uncomfortably Hot Area & 0.141 & 0.349 \\
Work in an Uncomfortably Cold Area & 0.075 & 0.263 \\
\hline
\end{tabular}

There are 946 observations. 
Table 3: Descriptive Statistics - Child Health Descriptive Statistics and Child Health Means by Employment Category

Child Health Variables:

Low Birth Weight

Preterm Birth

\section{Proportion of Hours Worked}

No Work

Greater than 0 and less than 20 Hours per Week

From 20 to 40 Hours per Week

40 or more Hours per Week

There are 3,546 observations.
Std. Dev.

0.244

0.237

Average by Employment Category:

Low Weight

0.083

Premature Birth

0.058

0.064

0.066

0.041

0.042

0.057 
Table 4: Descriptive Statistics of Explanatory Variables

Standard Variables:

Child Gender ( $=1$ if male, 0 if female)

Child's Birth Order

Black Dummy Variable

Hispanic Dummy Variable

Woman's Age

Woman's Body Mass Index (BMI)

Woman's Education

Marital Status (=1 if married)

Nonmaternal Family Income

Northeast Dummy Variable

South Dummy Variable

West Dummy Variable

Urban Area Dummy Variable

County Birth Rate (per person)

Proportion of Births to Women under 20

County Physician Rate (per 100 people)

County Hospital Bed Rate (per 100 people)

Pregnancy Behavior Variables:

Alcohol Once ( $=1$ if drank alcohol no more than once/month)

Alcohol More ( $=1$ if drank alcohol more than once/month)

Smoked One ( $=1$ if smoked no more than 1 pack/day)

Smoked More ( $=1$ if smoked more than 1 pack/day)

Medical visit ( $=1$ if visited a physician during pregnancy)

Visit Month (month of pregnancy of first physician visit)

Vitamin ( = 1 if took vitamin supplement during pregnancy)

Calories ( $=1$ if reduced caloric intake during pregnancy)

Salt ( $=1$ if reduced salt intake during pregnancy)

Diuretic ( $=1$ if took a diuretic during pregnancy)

Sonogram ( $=1$ if took a sonogram/ultrasound)

Amniocentesis ( $=1$ if took an amniocentesis)

Pregnancy Earnings (\$1000s)

\begin{tabular}{|c|c|c|c|}
\hline & $\underline{\text { Stand. }}$ & & Didn't \\
\hline Mean & Dev. & $\underline{\text { Worked }}$ & $\underline{\text { Work }}$ \\
\hline 0.512 & 0.500 & 0.512 & 0.512 \\
\hline 2.050 & 1.152 & $1.792 * * *$ & 2.685 \\
\hline 0.222 & 0.415 & $0.188 * * *$ & 0.305 \\
\hline 0.183 & 0.387 & $0.173 * *$ & 0.206 \\
\hline 27.607 & 4.588 & $27.906 * * *$ & 26.872 \\
\hline 23.543 & 4.992 & 23.485 & 23.688 \\
\hline 12.940 & 2.390 & $13.372 * * *$ & 11.878 \\
\hline 0.741 & 0.438 & $0.794 * * *$ & 0.610 \\
\hline 6.326 & 17.124 & $5.776 * * *$ & 7.680 \\
\hline 0.177 & 0.382 & 0.180 & 0.171 \\
\hline 0.355 & 0.479 & $0.365^{*}$ & 0.331 \\
\hline 0.205 & 0.404 & 0.198 & 0.223 \\
\hline 0.786 & 0.413 & $0.794 *$ & 0.768 \\
\hline 0.164 & 0.029 & $0.162 * * *$ & 0.168 \\
\hline 0.155 & 0.047 & $0.152 * * *$ & 0.163 \\
\hline 1.738 & 1.204 & 1.737 & 1.739 \\
\hline 5.842 & 3.941 & $5.932 * *$ & 5.622 \\
\hline 0.154 & 0.361 & $0.171 * * *$ & 0.111 \\
\hline 0.158 & 0.365 & 0.160 & 0.155 \\
\hline 0.176 & 0.381 & $0.163 * * *$ & 0.209 \\
\hline 0.072 & 0.258 & $0.056 * * *$ & 0.112 \\
\hline 0.992 & 0.090 & 0.992 & 0.992 \\
\hline 2.550 & 1.859 & $2.479 * * *$ & 2.725 \\
\hline 0.952 & 0.214 & $0.960 * * *$ & 0.931 \\
\hline 0.242 & 0.428 & 0.236 & 0.257 \\
\hline 0.512 & 0.500 & $0.530 * * *$ & 0.468 \\
\hline 0.015 & 0.122 & 0.013 & 0.020 \\
\hline 0.488 & 0.499 & $0.476 * *$ & 0.517 \\
\hline 0.024 & 0.153 & 0.021 & 0.030 \\
\hline 7.253 & 9.086 & $9.968 * * *$ & 0.000 \\
\hline
\end{tabular}

There are 3,546 observations in the full sample, 2,522 observations with women who worked during the pregnancy, and 1,024 observations with women who did not. The standard variables also include year dummy variables for the calendar year of birth. * indicates statistically significance difference in means (between women who did and did not work during their pregnancy) at the $10 \%$ level, ** at the $5 \%$ level, and $* * *$ at the $1 \%$ level. 
Table 5: The Effect of Pregnancy Employment on the Probability of Low Birth Weight (Logits)

\section{Pregnancy Employment Variables:}

Model 1:

Employed During Pregnancy

Model 2:

Proportion of Hours Worked During Pregnancy

Model 3:

Employed During Pregnancy

Proportion of Hours Worked During Pregnancy

Model 4:

Greater than 0 and less than 20 Hours per Wk.

From 20 to 40 Hours per Week

40 or more Hours per Week

Standard Variables

Pregnancy Behavior Variables

Pregnancy Earnings Variable

\section{Specification 1}

$$
-0.273 *
$$

$-0.337 *$

$(0.186)$

$-0.109$

$(0.233)$

$-0.150$

$(0.239)$

$-0.156$

$-0.252$

$(0.256)$

$-0.199$

$(0.266)$

$-0.145$

$$
-0.294
$$

$-0.232$

$(0.226)$

$-0.318$

$-0.070$

$(0.202)$

$-0.055$

$(0.206)$

$-0.030$

$-0.529 *$

$\underline{\text { Specification } 3}$

$\begin{array}{llll}-0.578 * * & (0.236) & -0.570 * * & (0.235)\end{array}$

$\begin{array}{lll}\text { Yes } & \text { Yes } & \text { Yes } \\ \text { No } & \text { Yes } & \text { Yes } \\ \text { No } & \text { No } & \text { Yes }\end{array}$

Standard errors are in parentheses. * indicates statistical significance at the $10 \%$ level, $* *$ at the $5 \%$ level, and $* * *$ at the $1 \%$ level. There are 3,546 observations used in the low birth weight model. 
Table 6: The Effect of Pregnancy Employment on the Probability of Preterm Birth (Logits)

\section{Pregnancy Employment Variables:}

Model 1:

Employed During Pregnancy

Model 2:

Proportion of Hours Worked During Pregnancy

Model 3:

Employed During Pregnancy

Proportion of Hours Worked During Pregnancy

Model 4:

Greater than 0 and less than 20 Hours per Wk.

From 20 to 40 Hours per Week

40 or more Hours per Week

Standard Variables

Pregnancy Behavior Variables

Pregnancy Earnings Variable $\underline{\text { Specification } 1}$

Specification 2

Specification 3

$\begin{array}{cccccc}-0.123 & (0.180) & -0.103 & (0.180) & -0.169 & (0.196) \\ 0.078 & (0.197) & 0.118 & (0.200) & 0.059 & (0.259) \\ & & & & & \\ -0.354 & (0.254) & -0.365 & (0.258) & -0.358 & (0.260) \\ 0.337 & (0.266) & 0.386 & (0.274) & 0.335 & (0.332) \\ & & & & & \\ -0.462^{*} & (0.254) & -0.461^{*} & (0.258) & -0.468^{*} & (0.258) \\ 0.135 & (0.215) & 0.162 & (0.215) & 0.126 & (0.239) \\ -0.116 & (0.235) & -0.072 & (0.237) & -0.135 & (0.289)\end{array}$

Yes

Yes

Yes

No

Yes

Yes

No

Yes

Standard errors are in parentheses. * indicates statistical significance at the $10 \%$ level, $* *$ at the $5 \%$ level, and $* * *$ at the $1 \%$ level. There are 3,546 observations used in the premature birth model. 
Table 7: The Effect of Pregnancy Employment from Each Trimester on Health at Birth

Low Birth Weight $\quad$ Preterm Birth

Model 1:

Employed During Pregnancy (First Trimester)

Employed During Pregnancy (Second Trimester)

$\begin{array}{cccc}0.167 & (0.260) & -0.332 & (0.301) \\ 0.204 & (0.302) & 1.024 * * * & (0.323) \\ -0.977 * * * & (0.242) & -1.057 * * * & (0.228)\end{array}$

Model 2:

Portion of Hours Worked (First Trimester)

$\begin{array}{llll}0.319 & (0.340) & 0.175 & (0.345)\end{array}$

Portion of Hours Worked (Second Trimester)

$\begin{array}{lll}-0.300 & (0.518) & 0.660\end{array}$

Portion of Hours Worked (Third Trimester)

$-0.477 \quad(0.434)-1.006 * * * \quad(0.368)$

Model 3:

Employed During Pregnancy (First Trimester)

$\begin{array}{lll}0.144 & (0.318) & -0.473\end{array}$

(0.392)

Portion of Hours Worked (First Trimester)

$\begin{array}{lll}0.020 & (0.481) \quad 0.170\end{array}$

Employed During Pregnancy (Second Trimester)

$0.171 \quad(0.352) \quad 0.686^{*}$

Portion of Hours Worked (Second Trimester)

0.092

Employed During Pregnancy (Third Trimester)

$-1.552 * * *$

$(0.614)$

0.742

$(0.545)$

Portion of Hours Worked (Third Trimester)

0.634

(0.389) $-1.418 * * *$

$(0.427)$

Model 4:

Employed 0 and 20 Hours (First Trimester)

$$
\begin{array}{cccc}
-0.035 & (0.310) & -0.533 & (0.385) \\
0.415 & (0.325) & -0.320 & (0.396) \\
0.427 & (0.473) & 0.040 & (0.455) \\
-0.053 & (0.355) & 0.546 & (0.397) \\
0.252 & (0.444) & 1.378 * * * & (0.426) \\
-0.322 & (0.691) & 0.787 & (0.616) \\
-1.510 * * * & (0.451) & -1.594 * * * & (0.375) \\
-1.005 * * * & (0.392) & -1.321 * * * & (0.375)
\end{array}
$$

Employed 20 to 40 Hours (First Trimester)

Employed 40 or more Hours (First Trimester)

Employed 0 and 20 Hours (Second Trimester)

Employed 20 to 40 Hours (Second Trimester)

Employed 40 or more Hours (Second Trimester)

Employed 0 and 20 Hours (Third Trimester)

Employed 20 to 40 Hours (Third Trimester)

Employed 40 or more Hours (Third Trimester)

$\begin{array}{llll}-0.549 & (0.473) & -0.965 * * & (0.434)\end{array}$

Standard errors are in parentheses. $*$ indicates statistical significance at the $10 \%$ level, $* *$ at the $5 \%$ level, and $* * *$ at the $1 \%$ level. There are 3,546 observations. These models include the standard variables but not the supplemental pregnancy behaviors variables or the pregnancy earnings variable. 
Table 8: The Effect of Pregnancy Employment on the Probability of Low Birth Weight (Logits)

Pregnancy Employment Variables:

Model 1:

Employed During Pregnancy

Preterm Birth

Model 2:

Proportion of Hours Worked During Pregnancy

Preterm Birth

Model 3:

Employed During Pregnancy

Proportion of Hours Worked During Pregnancy

Preterm Birth

Model 4:

Greater than 0 and less than 20 Hours per Wk.

From 20 to 40 Hours per Week

40 or more Hours per Week

Preterm Birth

Standard Variables

Pregnancy Behavior Variables

Pregnancy Earnings Variable

\section{Specification 1}

Specification 2

$$
\begin{array}{ccccc}
-0.341^{*} & (0.206) & -0.343 * & (0.210) & -0.269 \\
3.633 * * * & (0.198) & 3.680 * * * & (0.205) & 3.686 * *
\end{array}
$$

$$
\begin{array}{cccccc}
-0.579 * * * & (0.216) & -0.559 * * & (0.224) & -0.548 * & (0.304) \\
3.665 * * * & (0.198) & 3.713 * * * & (0.205) & 3.713 * * * & (0.205)
\end{array}
$$

$\begin{array}{llllll}0.082 & (0.274) & 0.035 & (0.276) & 0.034 & (0.277)\end{array}$

$\begin{array}{llllll}-0.645^{* *} & (0.291) & -0.587 * * & (0.298) & -0.577 & (0.376)\end{array}$

$3.668 * * * \quad(0.198) \quad 3.714 * * * \quad(0.205) \quad 3.714 * * * \quad(0.205)$

$$
\begin{array}{cccccc}
-0.157 & (0.261) & -0.191 & (0.261) & -0.191 & (0.263) \\
-0.247 & (0.235) & -0.243 & (0.248) & -0.243 & (0.276) \\
-0.785 * * * & (0.281) & -0.757 * * * & (0.282) & -0.757 * * & (0.265) \\
3.658 * * * & (0.199) & 3.699 * * * & (0.206) & 3.699 * * * & (0.206)
\end{array}
$$

Standard errors are in parentheses. * indicates statistical significance at the $10 \%$ level, $* *$ at the $5 \%$ level, and $* * *$ at the $1 \%$ level. There are 3,753 observations used in the low birth weight model. 
Table 9: The Effects of Pre-Pregnancy Employment

\section{Pregnancy Employment Variables:}

Model 1:

Employed During Pregnancy

Model 2:

Proportion of Hours Worked During Pregnancy

Model 3:

Employed During Pregnancy

Proportion of Hours Worked During Pregnancy

Model 4:

Greater than 0 and less than 20 Hours per Wk.

From 20 to 40 Hours per Week

40 or more Hours per Week

\section{Low Birth Weight $\quad \underline{\text { Preterm Birth }}$}

$-0.435^{* *} \quad(0.186) \quad-0.316^{*} \quad(0.196)$

$\begin{array}{llll}-0.182 & (0.196) & 0.065 & (0.216)\end{array}$

$-0.558 * * \quad(0.247) \quad-0.630 * * \quad(0.261)$

$0.187 \quad(0.247) \quad 0.461^{*} \quad(0.270)$

$\begin{array}{llll}-0.634 * * \quad(0.238) & -0.687 * * * & (0.251)\end{array}$

$\begin{array}{llll}-0.226 & (0.219) & -0.135 & (0.229)\end{array}$

$\begin{array}{llll}-0.471 * * & (0.233) & -0.152 & (0.247)\end{array}$

Standard Variables Yes Yes

Pregnancy Behavior Variables

No

No

Pregnancy Earnings Variable No No

Standard errors are in parentheses. * indicates statistical significance at the $10 \%$ level, ** at the $5 \%$ level, and $* * *$ at the $1 \%$ level. There are 3,546 observations in the low birth weight and premature birth models. 
Table 10: The Effect of Pregnancy Employment (Sibling Fixed Effects Models)

Pregnancy Employment Variables:

Model 1:

Employed During Pregnancy

Model 2:

Proportion of Hours Worked During Pregnancy

Model 3:

Employed During Pregnancy

Proportion of Hours Worked During Pregnancy

Model 4:

Greater than 0 and less than 20 Hours per Week

From 20 to 40 Hours per Week

40 or more Hours per Week

\section{Low Birth Weight}

$0.015 \quad(0.021) \quad 0.001$

$(0.020)$

$\begin{array}{llll}-0.004 & (0.025) \quad 0.011 \quad(0.024)\end{array}$

$\begin{array}{lll}0.025 & (0.025) & -0.004\end{array}$

$-0.021$

$(0.030)$

0.014

$-0.009$

$(0.023)$

$-0.001$

0.027

$(0.024)$

0.008

$(0.023)$

$-0.035$

$(0.031)$

Standard errors are in parentheses. * indicates statistical significance at the $10 \%$ level, ** at the $5 \%$ level, and $* * *$ at the $1 \%$ level. There are 1,212 observations used in the fixed effects low birth weight and premature birth models. 
Appendix Table: The Effects of the Other Covariates (Logit Models)

\begin{tabular}{|c|c|c|c|c|}
\hline \multirow[b]{2}{*}{ Intercept } & \multicolumn{2}{|c|}{ Low Birth Weight } & \multicolumn{2}{|c|}{ Preterm Birth } \\
\hline & -1.737 & $(1.565)$ & -1.145 & $(1.225)$ \\
\hline Child Gender (male) & $-0.464 * * *$ & $(0.145)$ & -0.112 & $(0.136)$ \\
\hline Child's Birth Order & -0.112 & $(0.073)$ & -0.094 & $(0.075)$ \\
\hline Black Dummy Variable & 0.308 & $(0.203)$ & -0.165 & $(0.200)$ \\
\hline Hispanic Dummy Variable & 0.140 & $(0.233)$ & 0.005 & $(0.213)$ \\
\hline Woman's Age & -0.020 & $(0.034)$ & 0.009 & $(0.033)$ \\
\hline Woman's Body Mass Index & $-0.062 * * *$ & $(0.018)$ & -0.011 & $(0.014)$ \\
\hline Woman's Education & -0.028 & $(0.040)$ & 0.035 & $(0.037)$ \\
\hline Marital Status & $-0.513 * * *$ & $(0.181)$ & $-0.641 * * *$ & $(0.176)$ \\
\hline Nonmaternal Family Income & 0.005 & $(0.005)$ & -0.003 & $(0.004)$ \\
\hline Northeast Dummy Variable & 0.083 & $(0.239)$ & -0.096 & $(0.232)$ \\
\hline South Dummy Variable & -0.056 & $(0.196)$ & -0.042 & $(0.191)$ \\
\hline West Dummy Variable & -0.320 & $(0.255)$ & -0.085 & $(0.231)$ \\
\hline Urban Area Dummy Variable & 0.262 & $(0.214)$ & $0.331 *$ & $(0.204)$ \\
\hline County Birth Rate & -3.537 & $(3.276)$ & $-7.841 * * *$ & $(3.168)$ \\
\hline Proportion of Births to Women under 20 & $5.265 * * *$ & $(1.903)$ & $4.755^{* * *}$ & $(1.837)$ \\
\hline County Physician Rate & 0.022 & $(0.080)$ & 0.027 & $(0.075)$ \\
\hline County Hospital Bed Rate & -0.026 & $(0.025)$ & -0.036 & $(0.025)$ \\
\hline Alcohol Once & 0.204 & $(0.200)$ & -0.225 & $(0.202)$ \\
\hline Alcohol More & -0.003 & $(0.201)$ & -0.309 & $(0.205)$ \\
\hline Smoked One & $0.375^{* *}$ & $(0.185)$ & -0.029 & $(0.191)$ \\
\hline Smoked More & $0.735 * * *$ & $(0.241)$ & -0.042 & $(0.273)$ \\
\hline Medical visit & 0.929 & $(1.083)$ & - & - \\
\hline Visit Month & 0.011 & $(0.041)$ & -0.040 & $(0.042)$ \\
\hline Vitamin & -0.102 & $(0.298)$ & -0.345 & $(0.282)$ \\
\hline Calories & 0.222 & $(0.175)$ & 0.063 & $(0.171)$ \\
\hline Salt & 0.135 & $(0.156)$ & -0.103 & $(0.147)$ \\
\hline Diuretic & 0.433 & $(0.464)$ & 0.550 & $(0.428)$ \\
\hline Sonogram & $0.402 * *$ & $(0.174)$ & $0.515 * * *$ & $(0.194)$ \\
\hline Amniocentesis & $0.816^{* *}$ & $(0.347)$ & $0.870 * * *$ & $(0.325)$ \\
\hline Pregnancy Earnings & -0.009 & $(0.011)$ & 0.006 & $(0.010)$ \\
\hline
\end{tabular}

Standard errors are in parentheses. * indicates statistical significance at the $10 \%$ level, ** at the 5\% level, and $* * *$ at the $1 \%$ level. There are 3,546 observations in the low birth weight and premature birth models. The regressions also include year dummy variables for the calendar year of birth (results not shown). These regression estimates were taken from model 1 (specification 3) in tables 4 and 5 for low birth weight and preterm birth, respectively. Medical visit is eliminated from the preterm birth model because it is a perfect predictor. 